\title{
Article
}

\section{Changing stroke mortality trends in middle-aged people: an age-period- cohort analysis of routine mortality data in persons aged 40 to 69 in England}

Sutton, Chris J, Marsden, Jenny, Watkins, Caroline L, Leathley, Michael J and Dey, Maria Paola

Available at https://clok.uclan.ac.uk/1112/

Sutton, Chris J orcid iconORCID: 0000-0002-6406-1318, Marsden, Jenny, Watkins, Caroline L orcid iconORCID: 0000-0002-9403-3772, Leathley, Michael $J$ and Dey, Maria Paola (2010) Changing stroke mortality trends in middleaged people: an age-period-cohort analysis of routine mortality data in persons aged 40 to 69 in England. Journal of Epidemiology \& Community Health, 64 (6). pp. 523-529. ISSN 0143-005X

It is advisable to refer to the publisher's version if you intend to cite from the work. http://dx.doi.org/10.1136/jech.2008.086785

For more information about UCLan's research in this area go to http://www.uclan.ac.uk/researchgroups/ and search for <name of research Group>.

For information about Research generally at UCLan please go to http://www.uclan.ac.uk/research/

All outputs in CLoK are protected by Intellectual Property Rights law, including Copyright law. Copyright, IPR and Moral Rights for the works on this site are retained by the individual authors and/or other copyright owners. Terms and conditions for use of this material are defined in the policies page. 


\title{
TITLE PAGE
}

\section{Full title}

Changing stroke mortality trends in middle-aged people: an age-period-cohort analysis of routine mortality data in persons aged 40 to 69 in England

\section{Corresponding Author Address}

Chris J Sutton PhD, Senior Lecturer in Medical Statistics, School of Public Health and Clinical Sciences, Faculty of Health, University of Central Lancashire, Preston, PR1 2HE, UK.

FAX: 44 (0) 1772892914 Tel: 44 (0) 1772892783 Email: cjsutton@uclan.ac.uk

\author{
Authors \\ Chris J Sutton, PhD \\ Jenny Marsden, $\mathrm{PhD}$ \\ Caroline L Watkins, PhD \\ Michael J Leathley, PhD \\ Paola Dey, MD \\ University of Central Lancashire, Preston, UK.
}

Keywords Epidemiology, stroke, risk factor, cohort effect, statistical model

Word count 2810 


\begin{abstract}
Background

In the United Kingdom, overall stroke mortality has declined. A similar trend has been seen in coronary heart disease, although recent reports suggest this decline might be levelling off in middle-aged adults.
\end{abstract}

Aim

To investigate recent trends in stroke mortality amongst those aged 40-69 years in England.

\title{
Methods
}

We used routine annual aggregated stroke death and population data for England for the years 1979-2005 to investigate time trends in gender-specific mortality rates for adults aged 40 to 69 years. We applied log-linear modelling to isolate effects attributable to age, linear 'drift' over time, time period and birth cohort.

\section{Results}

Between 1979 and 2005, age-standardised stroke mortality aged 40 to 69 years dropped from 93 to 30 per 100,000 in men and from 62 to 18 per 100,000 in women. Mortality was higher in older age groups, but the difference between the older and younger age groups appears to have decreased over time for both sexes. Modelling of the data suggests an average annual reduction in stroke deaths of $4.0 \%$ in men and $4.3 \%$ in women, although this decrease has been particularly marked in the last few years. However, we also observed a relative rate increase in mortality amongst those born since the mid-1940s compared with earlier cohorts; this appears to have been sustained in men, which explains the levelling off in the rate of mortality decline observed in recent years in the younger middle-aged.

\section{Conclusions}

If observed trends in middle-aged adults continue, overall stroke mortality rates may start to increase again. 


\section{INTRODUCTION}

Mortality from stroke has substantially declined in England and Wales (E\&W) over the last five decades.[1] Similar declines have been observed in many countries worldwide.[2, 3] In the absence of robust national population data on stroke incidence or survival, it is unclear how much of these reductions in mortality are due to prevention and how much to changes in stroke management. The reports of carefully-assembled regional population-based cohorts have produced inconsistent results. In the presence of declining mortality, some cohorts have exhibited a reduction in incidence in the presence of stable case-fatality (eg, Oxfordshire: UK [4]); others have shown stable incidence but improving survival (eg, Dijon: France [5]); while improvements in both incidence and survival have also been observed, at least in men, in the Framingham cohort.[6] Therefore, it is unclear whether the decline is due to improvements in primary or secondary prevention of stroke or its management. In those countries which have seen a decline in mortality, improved population risk factor profiles for stroke have been observed. The reasons given for this improvement include better social conditions, [7] declines in smoking prevalence $[4,6]$ and increased uptake of preventative medication such as antihypertensives,[4, 6] lipid-lowering drugs [4] and antiplatelets.[4-6]

There is growing concern that recent increases in the prevalence of obesity and diabetes will result in higher premature mortality rates.[8] However, to date there has been little evidence from population-based surveillance data to support these concerns. [9] Recent analyses of temporal trends in coronary heart disease (CHD) mortality, using national datasets from the United States (US) and from E\&W, have suggested that the decline in CHD mortality has levelled off in middle-aged adults.[10,11] Those who suffer an ischaemic stroke share similar risk factors to those who suffer from CHD. Differences between stroke mortality trends and those observed for CHD mortality, which began to decline only in the 1980s, have been explained by differing mortality trends between stroke subtypes: primary intracerebral haemorrhage and ischaemic stroke.[1] It has been suggested that the early decline in stroke mortality during the last 5 decades was mainly due to decreases in fatal primary intracerebral haemorrhage while ischaemic stroke mortality trends have more closely followed those observed in CHD.[1] There is a suggestion of an increasing risk of mortality for cohorts born after 1940 from a study of stroke mortality trends in Spain.[12] However, the data in that study were insufficiently mature to determine if these trends were any more than artefactual or short-term. Therefore, we have investigated trends in stroke mortality in middle-aged people in England using more recent data from 1979 to 2005.

\section{METHODS}

Stroke was defined using the following ICD codes: ICD-9 430 to 438 for data preceding 2001 and ICD-10 I60 to I69 for data from 2001 onwards. Codes for subarachnoid haemorrhage were not included. These codes have been used by others investigating stroke trends $[13,14]$ and were chosen to overcome some of the problems of misclassification caused by changes in coding of different subtypes of stroke over the study period.[15] The number of deaths from stroke for each year from 1979 to 2005 in England were collated as one-year age-bands for each sex for persons aged 40 to 69 from aggregate data supplied by the Office of National Statistics (ONS), which also supplied population estimates for England for the same years by one-year age-band and sex. Birth cohorts were identified by estimating the year of birth from the age at death and the year of death. 
To examine general stroke mortality trends for each sex, data were initially grouped by threeyear age-bands (40-42, ., 67-69) and age-standardised mortality rates estimated for each year, using 1979 as the reference population. Further aggregation of the data by three-year periods was then undertaken to form nine periods $(1979-81, \ldots, 2003-5)$ and 18 birth cohorts (1909-1914, ..., 1960-1965) and trends in age-specific rates by period and birth cohort examined for each sex.

Log-linear 'Poisson' modelling was then undertaken to determine the form of individual one-year age, period and cohort effects on mortality rates using the Epi package within the statistical software R. Data sets for men and women were modelled separately, each with thirty age bands, 27 periods and 56 cohorts. Estimation was via maximum-likelihood. We parameterised so that: age effects were relative to the first period (1979); period and cohort effects were constrained to be equal to zero, on average, and with zero slope; the slope was attributed to a 'drift' over time.[16] We produced smoothed trend plots of the estimated age, period and birth cohort effects using natural cubic splines, using six, five and 11 internal knots at which to join the piecewise-continuous cubic polynomials for age, period and cohort, respectively[17]; this smoothing was done to reduce noise, and the number of knots chosen is also consistent with the recommendation of Carstensen as we had a specific interest in birth cohort and, hence, used more knots in this plot of this effect.[16] Approximate 95\% confidence intervals were also plotted for each estimated effect.

Sensitivity analyses were undertaken by varying the order of fitting cohort and period terms and the number of knots. We also investigated the effect of allocating 'drift' entirely to cohort as a relatively extreme-case scenario.

\section{RESULTS}

In adults aged 40 to 69 years, there were a total of 111,219 stroke deaths in men over the 27 year period (ranging from 19,066 in 1979-1981 to 7,444 in 2003-2005) and a total of 79,541 stroke deaths in women (ranging from 14,380 in 1979-1981 to 4,767 in 2003-2005). The stroke mortality rate in both sexes declined over these three decades (Figure 1: left panel). Mortality rates were higher in men compared to women but declined similarly (Figure 1: right panel). In 1979, the age-standardised stroke mortality rate was $93 \cdot 3$ per $100,000(6,756$ deaths) and 62.1 per 100,000 (5,179 deaths) in men and women aged 40 to 69 years, respectively. By 2005, this had reduced to 29.6 per 100,000 (2,348 deaths) and $17 \cdot 6$ per 100,000 (1,456 deaths) in men and women, respectively. During the study period, mortality was consistently higher in older age groups, but the difference between the older and younger age groups appears to have decreased over time for both sexes (Figures 2 and 3: top right).

Examination of birth cohorts indicates a continuing decline in the mortality rate in older cohorts but an apparent decrease in the rate of decline in mortality with more recent cohorts. (Figures 2 and 3: bottom right)

Modelling the mortality rate, we extracted the age and 'drift' to assess the non-linear changes in mortality rate for the time periods and birth cohorts separately. The linear 'drift' showed an average annual reduction in stroke deaths of $4.0 \%$ amongst men and $4.3 \%$ amongst women. The residual period effect showed a peaking in the late 1980s and again around 2000, but a marked decrease in mortality in the last few years relative to previous periods; this was again observed for both men and women (Figure 4). Examination of the residual cohort effect showed that for those born before the mid-1940s there was little non-linear change, but there was subsequently a pronounced increase in residual mortality rate in those born after the mid- 
1940s in both sexes relative to earlier cohorts (Figure 4). There is some suggestion that this increase is not sustained in women in the most recent cohorts but the number of deaths is small as evinced by the wide confidence intervals. However, the trend is sustained in men, in whom there are more deaths, and the confidence intervals are narrower.

We repeated the modelling by extracting the non-linear period effects before the non-linear cohort effects, but the observed patterns remained very similar (data not presented). On varying the number of knots for age, period and cohort, there was no substantive change to the overall form of the effect plots (data not presented). Even in the extreme case, when we allocated the 'drift' to cohort alone, the overall cohort effect confirms a recent plateau in declining rates, sustained in men but not women (Figure 5).

\section{DISCUSSION}

This is the first age-period-cohort study of trends in stroke mortality undertaken in the English population for two decades.[13] The marked decline in stroke mortality, which has been observed in the whole population during this time,[1] is also apparent in middle-aged adults in both sexes. This period has seen considerable changes in the population distribution of some risk factors for stroke with a decline in the prevalence of smoking and mean blood pressure.[18,19] It has also been a period of more effective management of stroke patients with increased uptake of secondary prevention,[4] greater access to brain imaging,[20,21] and the widespread introduction of stroke units.[20] However, as with CHD mortality in $\mathrm{E} \& \mathrm{~W}$, there is some evidence that the decline in stroke mortality is levelling off in younger middle-aged groups included in our study in recent years. This appears to be a cohort or generational effect, which begins in cohorts born in the mid-1940s (Figure 4). This effect appears to have been sustained in men but not in women. However, care must be taken in over-interpreting information from the small number of deaths among women in these age groups (Figures 3 and 4).

This cohort effect is likely to be due primarily to exposure to risk factors for stroke rather than changes in clinical management which would be expected to act across age groups at a similar time and, hence, manifest as period effects. It is unlikely to be solely explained by plateauing in the decline in smoking prevalence in UK populations as this was first observed in cohorts born in the mid-1950s in men and late 1950s in women.[18] Concerns about plateauing in the decline in population mean blood pressure have been restricted to children and adolescents born in the last three decades and would not have affected the cohorts included in this study.[22]

Obesity may be a more plausible candidate to explain the changing cohort trends in stroke mortality. For England, there is some evidence that obesity rates started to increase in adults in the early 1980 s and the relative increase over the subsequent two decades was greater for those under 45 at this time.[23-25] In Japan, levelling off of the declines in stroke mortality has occurred in more recent cohorts than observed in our study, and in men a decade before women.[14] This corresponds to increases in the prevalence of obesity and impaired glucose tolerance observed in similar cohorts of Japanese men.[26] However, although there is strong evidence that obesity is associated with an increased risk of stroke mortality,[27] the evidence to support an independent association is conflicting.[28,29] Some suggest that this may be due to the attenuating effect of other risk factors, such as diabetes and hypertension, which are higher in obese populations, and that obesity is part of their early causal pathway.[27,28] Others point out the limitations of measuring body mass index and report that central obesity 
is independently associated with stroke mortality.[29] The prevalence of diabetes has also increased over the last couple of decades in England, although to a greater extent in older age groups. [25] In a recent review of secular trends in cardiovascular risk factors using survey data from the US, diabetes was the only stroke risk factor which has not decreased over time among those who are obese.[30] Physical inactivity is also associated with higher stroke mortality,[31] but there is no robust evidence that overall physical activity levels have declined in the English population over that last two decades and some evidence that it may have increased more recently, particularly in middle-aged adults.[32, 33] It is unclear what the trends are among obese individuals.[23]

As well as cohort effects, there is also evidence of period effects. Some of these earlier deviations from linear trend might be explained by changes in disease coding procedures. The ONS altered coding practice in 1984, in 1993 and in 2001, which are consistent with deviations in linear trend observed for time period in our model.[34] In each of these years, there was a change in the attribution of the underlying cause of death. In 1984, this resulted in an increase in stroke mortality rates, while the change which occurred in 1993 led to a decrease. In 2001, ONS also introduced ICD-10, the main effect of which was a broadening of some of the disease groups to reflect more recent concepts about the pathology and aetiology of stroke: for example, deaths previously coded as arteriosclerotic dementia are now coded as ischaemic stroke. There was a consequent increase in the stroke mortality rate.[35] However, since 2001, there has been a further decline in mortality rates, which cannot be explained by changes in coding practice, but which might be explained by better stroke management. In the absence of additional information on trends in incidence of disease and case-fatality, it is not possible to speculate further on its origin.

There are other limitations to age-period-cohort modelling of routine data. We used aggregate mortality data in which the actual date of birth was not determinable, producing overlapping cohorts by subtracting age at death from year of death. Mortality rates may be sensitive to population estimates. Population estimates for the most recent time period for our study have been revised since our initial analysis. However, re-analysis using these revised estimates did not alter our findings. It has been estimated that routine statistics miss up to a quarter of stroke-related deaths, because they are classified as deaths due to other causes.[13] This would only be a problem in this study were misclassifications greater for some types of strokes than others and if the distribution of these stroke types had changed over the period of study. Both are possible.

Examination of disease trends is important to assess emerging health threats, monitor prevention programmes and plan health services. One possible interpretation of our analysis is that the mortality benefits from recent improvements in stroke management are not fully realised in cohorts of adults, particularly men, born since the mid-1940s because, compared to previous cohorts, they are at increased risk of stroke from risk factors such as obesity and diabetes. This increased risk has not, as yet, manifest as an increase in overall stroke mortality because the number of deaths in these cohorts is still relatively small compared to the overall number of deaths from stroke. However, were the marked recent period decline in rates not sustained, then a levelling off or increase in overall stroke mortality rates could become evident as these cohorts grow older. Further research is needed to confirm the risk factors responsible for cohort changes. Population-based approaches have been more effective and efficient in reducing vascular mortality than targeted approaches which identify and treat high risk populations.[36,37] Therefore, there needs to be a greater emphasis on 
identifying modifiable stroke risk factors and modifying lifestyle behaviour in entire populations and, especially, in younger adults. 


\section{WHAT THIS PAPER ADDS}

\section{What is already known on this subject?}

There are concerns that the increasing prevalence of obesity and diabetes may lead to greater premature mortality, but there has been limited population evidence of such an effect. It has been reported that declines in coronary heart disease rates have levelled off in middle-aged populations. This study examines if similar effects are seen in stroke mortality.

\section{What does this study add?}

There has been a levelling off in the decline in the rate of stroke mortality amongst younger middle-aged adults, particularly in men, due to cohort changes in those born since the mid1940s. Increasing stroke risk factors in this age group is the most likely explanation. If these trends continue, overall stroke mortality rates may start to increase again. There needs to be a greater emphasis on identifying modifiable stroke risk factors, and promoting lifestyle changes, in younger adults and in whole populations. 


\section{ACKNOWLEDGEMENTS AND FUNDING PAGE}

\section{Acknowledgements}

None

\section{Competing Interests}

All authors have declared no conflicts of interest.

\section{Funding}

None

\section{Licence Statement}

The Corresponding Author has the right to grant on behalf of all authors and does grant on behalf of all authors, an exclusive licence (or non-exclusive for government employees) on a worldwide basis to the BMJ Publishing Group Ltd and its Licensees to permit this article to be published in Journal of Epidemiology and Community Health and any other BMJPGL products to exploit all subsidiary rights, as set out in our licence

http://jech.bmj.com/ifora/licence.pdf. 


\section{FIGURE LEGENDS}

Figure 1: Age-standardised stroke mortality rate (left panel) and log (base 10) rate (right panel) in England: men and women aged 40 to 69 years

Figure 2: Stroke death rates in England 1979-2005: men aged 40-69 years (Top left panel: age-specific rates by period of birth; top right panel: period-specific rates by age; bottom right panel: cohort-specific rates by age; bottom left panel: age-specific rates by period of death)

Figure 3: Stroke death rates in England 1979-2005: women aged 40-69 years (Top left panel: age-specific rates by period of birth; top right panel: period-specific rates by age; bottom right panel: cohort-specific rates by age; bottom left panel: age-specific rates by period of death)

Figure 4: Estimated rates attributable to age (leftmost curve) and non-linear rate ratios for and birth cohort (middle curve) and period of death (rightmost curve): men and women

Figure 5: Estimated rates attributable to age (leftmost curve), rate ratio (including linear 'drift') for birth cohort (middle curve) and non-linear rate ratio for period of death (rightmost curve): men and women 


\section{REFERENCES}

1. Lawlor DA, Davey Smith G, Leon DA, Sterne JAC, Ebrahim S. Secular trends in mortality by stroke subtype in the $20^{\text {th }}$ century: a retrospective analysis. Lancet 2002;360:1818-23.

2. Sarti C, Rastenyte D, Cepaitis Z, Tuomilehto J. International trends in mortality from stroke, 1968 to 1994. Stroke 2000;31:1588-601.

3. National Heart, Lung, and Blood Institute. Morbidity and mortality: 2007 Chart book on cardiovascular, lung, and blood diseases [monograph on the Internet]. Bethesda, MD: National Institute of Health; 2007 [cited 2008 Dec 24]. Available from: http://www.nhlbi.nih.gov/resources/docs/07-chtbk.pdf.

4. Rothwell PM, Coull AJ, Giles MF, Howard SC, Silver LE, Bull LM, et al.; Oxford Vascular Study. Change in stroke incidence, mortality, case-fatality, severity and risk factors in Oxfordshire, UK from 1981 to 2004. Lancet 2004;363:1925-33.

5. Benatru I, Rouaud O, Durier J, Contegal F, Couvreur G, Bejot Y, et al. Stable stroke incidence rates but improved case-fatality in Dijon, France, from 1985 to 2004 . Stroke 2006;37:1674-79.

6. Carandang R, Seshadri S, Beiser A, Kelly-Hayes M, Kase CS, Kannel WB, et al. Trends in incidence, lifetime risk, severity and 30 day mortality of stroke over the past 50 years. JAMA 2006;296:2939-46.

7. Amiri M, Kunst AE, Janssen F, Mackenbach JP. Cohort-specific trends in stroke mortality in seven European countries were related to infant mortality rates. J Clin Epidem 2006;59:1295-1302.

8. Olshansky SJ, Passaro DJ, Hershow RC, Layden J, Carnes BA, Brody J, et al. A potential decline in life expectancy in the United States in the 21 st century. N Engl J Med. 2005;352:1138-45.

9. Basham P, Luik J. Is the obesity epidemic exaggerated? Yes. BMJ. 2008;336:244.

10. Ford ES, Capewell S. Coronary heart disease mortality among young adults in the US from 1980 through 2002. Concealed levelling of mortality rates. J Am Coll Cardiol 2007;50:2128-32.

11. O'Flaherty M, Ford E, Allender S, Scarborough P, Capewell S. Coronary heart disease trends in England and Wales from 1984 to 2004: concealed levelling of mortality rates among young adults. Heart 2008;94:178-81.

12. Medrano MJ, Lopez-Abente G, Barrado MJ, Pollan M, Almazan J. Effect of age, birth cohort and period of death on cerebrovascular mortality in Spain, 1952 to 1991. Stroke 1997;28:40-4.

13. Wolfe CDA, Burney PGJ. Is stroke mortality on the decline in England? Am J Epidemiol 1992;136:558-65. 
14. Ma E, Takahashi H, Mizuno A, Okada M, Yamagishi K, Iso H. Stratified age-periodcohort analysis of stroke mortality in Japan, 1960 to 2000. J Stroke Cerebrovasc Dis 2007;16:91-102.

15. Goldacre MJ, Duncan M, Griffiths M, Rothwell PM. Mortality rates for stroke in England from 1979 to 2004: trends, diagnostic precision, and artifacts. Stroke 2008;39:2197-203.

16. Carstensen B. Age-period-cohort models for the Lexis diagram. Stat Med 2007;26:301845 .

17. Heuer C. Modeling of time trends and interactions in vital rates using restricted regression splines. Biometrics 1997;53:161-77.

18. Davy M. Time and generational trends in smoking among men and women in Great Britain, 1972-2004/5. Health Stat Q 2006;32:35-43.

19. Primatesta P, Poulter NR. Improvement in hypertension management in England: results from the Health Survey for England 2003. J Hypertens 2006;24:1187-92.

20. Clinical Evaluation and Effectiveness Unit, Royal College of Physicians. National sentinel stroke audit 2004: concise reports [monograph on the Internet]. London: Royal College of Physicians; 2005 [cited 2008 Dec 24]. Available from:

http://www.rcplondon.ac.uk/pubs/books/strokeaudit/strokeaudit2004.pdf.

21. Lindley RI, Amayo EO, Marshall J, Sandercock PAG, Dennis M, Warlow CP. Hospital services for patients with acute stroke in the United Kingdom: the Stroke Association survey of consultant opinion. Age Ageing 1995;24:525-32.

22. McCarron P, Smith GD, Okasha M. Secular changes in blood pressure in childhood, adolescence and young adulthood: systematic review of trends from 1948 to 1998. J Hum Hypertens 2002;16:677-89.

23. Knight I. The heights and weights of adults in Great Britain. OPCS Social Survey Division. London: HMSO; 1984.

24. Prescott-Clarke P, Colhoun H. Health Survey for England 1994: Volume 1. London: Stationery Office Books; 1996.

25. Health Survey for England 2006 [database on the Internet]. London: The Information Centre, Lifestyles Statistics. January 2008 [cited 2008 Dec 24]. Available from: http://www.ic.nhs.uk/webfiles/publications/HSE06/ADULT\%20TREND\%20TABLES\%202 006.xls.

26. Kuzuya M, Ando F, Iguchi A, Shimokata H. Age-specific change of prevalence of metabolic syndrome: longitudinal observation of large Japanese cohort. Atherosclerosis 2007;191:305-12.

27. Prospective Studies Collaboration. Body-mass index and cause-specific mortality in 900 000 adults: collaborative analyses of 57 prospective studies. Lancet 2009;373:1083-96. 
28. Hart CL, Hole DJ, Davey Smith G. Risk factors and 20-Year stroke mortality in men and women in the Renfrew/Paisley study in Scotland. Stroke 1999;30:1999-2007.

29. Suk S-H, Sacco RL, Boden-Albala B, Cheun JF, Pittman JG, Elkind MS, et al. Abdominal obesity and risk of ischemic stroke the Northern Manhattan stroke study. Stroke 2003;34:1586-92.

30. Gregg EW, Cheng YJ, Cadwell BL, Imperatore G, Williams DE, Flegal KM, et al. Secular trends in cardiovascular disease risk factors according to body mass index in US adults. JAMA 2005;293:1868-74.

31. Wendel-Vos GC, Schuit AJ, Feskens EJ, Boshuizen HC, Verschuren WM, Saris WH, et al. Physical activity and stroke. A meta-analysis of observational data. Int J Epidemiol 2004;33:787-98

32. Stamatakis E, Ekeland U, Wareham NJ. Temporal trends in physical activity in England: The Health Survey for England 1991 to 2004. Prev Med 2007;45:416-23.

33. Ed. Craig R, Mindell J. Health Survey 2006. Cardiovascular Disease and Risk Factors [monograph on the Internet]. Leeds: The Information Centre; 2008 [cited 2008 Dec 24]. Available from: http://www.ic.nhs.uk/pubs/hse06cvdandriskfactors

34. Office for National Statistics (ONS). Mortality statistics: cause 2001. London: HMSO; 2002. Series DH2, No.28.

35. Griffiths C, Brock A, Rooney C. The impact of introducing ICD-10 on trends in mortality from circulatory diseases in England and Wales. Health Stat Q 2004;22:14-20.

36. Tunstall-Pedoe H, Connaghan J, Woodward M, Tolonen H, Kuulasmaa K. Pattern of declining blood pressure across replicate population surveys of the WHO MONICA project, mid-1980s to mid-1990s, and the role of medication. BMJ 2006;332:629-35.

37. Unal B, Critchley JA and Capewell S. Modelling the decline in coronary heart disease deaths in England and Wales, 1981-2000: comparing contributions from primary prevention and secondary prevention. BMJ 2005;331:614. 


\section{APPENDIX}

Table 1: Mortality rates (per 100,000) in men aged 40-69 in England during 1979-2005, in three-year bands

\begin{tabular}{|c|c|c|c|c|c|c|c|c|c|}
\hline $\begin{array}{l}\text { Age } \\
\text { group }\end{array}$ & $\begin{array}{l}1979- \\
1981\end{array}$ & $\begin{array}{l}1982- \\
1984\end{array}$ & $\begin{array}{l}1985- \\
1987\end{array}$ & $\begin{array}{l}1988- \\
1990\end{array}$ & $\begin{array}{l}1991- \\
1993\end{array}$ & $\begin{array}{l}1994- \\
1996\end{array}$ & $\begin{array}{l}1997- \\
1999\end{array}$ & $\begin{array}{l}2000- \\
2002\end{array}$ & $\begin{array}{l}2003- \\
2005\end{array}$ \\
\hline $40-42$ & 5.8 & 4.3 & 3.9 & 3.9 & 3.4 & 4.4 & 3.9 & 3.7 & 4.0 \\
\hline $43-45$ & 10.3 & 8.1 & 7.5 & 6.0 & 5.7 & 5.6 & 5.8 & 6.0 & 5.3 \\
\hline $46-48$ & 15.4 & 13.4 & 11.8 & 10.4 & 8.9 & 8.3 & 8.0 & 8.1 & 8.2 \\
\hline $59-51$ & 26.3 & 21.5 & 20.4 & 16.6 & 15.4 & 13.5 & 12.3 & 12.8 & 10.2 \\
\hline $52-54$ & 38.9 & 33.3 & 29.6 & 23.2 & 22.9 & 20.4 & 17.5 & 16.7 & 16.1 \\
\hline $55-57$ & 58.6 & 48.6 & 43.5 & 40.6 & 35.9 & 29.7 & 27.6 & 23.1 & 20.8 \\
\hline $58-60$ & 90.4 & 81.2 & 77.7 & 59.8 & 55.7 & 47.5 & 44.1 & 37.4 & 30.7 \\
\hline $61-63$ & 135.7 & 122.7 & 115.7 & 97.6 & 87.7 & 71.8 & 64.7 & 57.0 & 48.1 \\
\hline 64-66 & 216.3 & 196.5 & 172.8 & 156.1 & 134.7 & 113.7 & 102.5 & 85.6 & 74.3 \\
\hline $67-69$ & 333.5 & 293.6 & 278.0 & 238.7 & 209.9 & 177.8 & 156.3 & 142.0 & 116.2 \\
\hline
\end{tabular}

Table 2: Mortality rates (per 100,000) in women aged 40-69 in England during 1979-2005, in three-year bands

\begin{tabular}{|c|c|c|c|c|c|c|c|c|c|}
\hline $\begin{array}{l}\text { Age } \\
\text { group }\end{array}$ & $\begin{array}{l}1979- \\
1981\end{array}$ & $\begin{array}{l}1982- \\
1984\end{array}$ & $\begin{array}{l}1985- \\
1987\end{array}$ & $\begin{array}{l}1988- \\
1990\end{array}$ & $\begin{array}{l}1991- \\
1993\end{array}$ & $\begin{array}{l}1994- \\
1996\end{array}$ & $\begin{array}{l}1997- \\
1999\end{array}$ & $\begin{array}{l}2000- \\
2002\end{array}$ & $\begin{array}{l}2003- \\
2005\end{array}$ \\
\hline $40-42$ & 4.2 & 3.5 & 3.2 & 3.1 & 2.9 & 2.8 & 2.6 & 2.8 & 1.9 \\
\hline $43-45$ & 5.9 & 4.9 & 6.1 & 4.4 & 3.8 & 3.7 & 4.5 & 3.7 & 3.0 \\
\hline $46-48$ & 11.3 & 8.4 & 8.1 & 6.1 & 5.0 & 5.6 & 5.7 & 6.0 & 5.1 \\
\hline $59-51$ & 17.1 & 13.4 & 12.2 & 9.9 & 8.1 & 7.2 & 8.5 & 7.8 & 6.3 \\
\hline $52-54$ & 25.7 & 21.4 & 18.8 & 14.3 & 13.2 & 12.3 & 10.4 & 9.4 & 9.5 \\
\hline $55-57$ & 36.7 & 32.6 & 25.7 & 24.8 & 19.9 & 17.0 & 15.7 & 13.7 & 12.0 \\
\hline $58-60$ & 56.8 & 51.3 & 47.1 & 36.9 & 36.0 & 28.1 & 27.8 & 21.6 & 17.4 \\
\hline $61-63$ & 88.8 & 78.4 & 73.7 & 62.5 & 53.1 & 44.6 & 40.5 & 31.5 & 27.6 \\
\hline 64-66 & 142.8 & 126.3 & 114.1 & 99.0 & 88.9 & 75.9 & 65.4 & 54.4 & 46.9 \\
\hline $67-69$ & 222.5 & 198.9 & 192.6 & 164.0 & 144.8 & 119.1 & 103.0 & 89.5 & 75.7 \\
\hline
\end{tabular}

Deaths: Men - Overall 111,219 (ranging from 19,066 in 1979-1981 to 7,444 in 2003-2005). Women - Overall 79,541 (ranging from 14,380 in 1979-1981 to 4,767 in 2003-2005). 

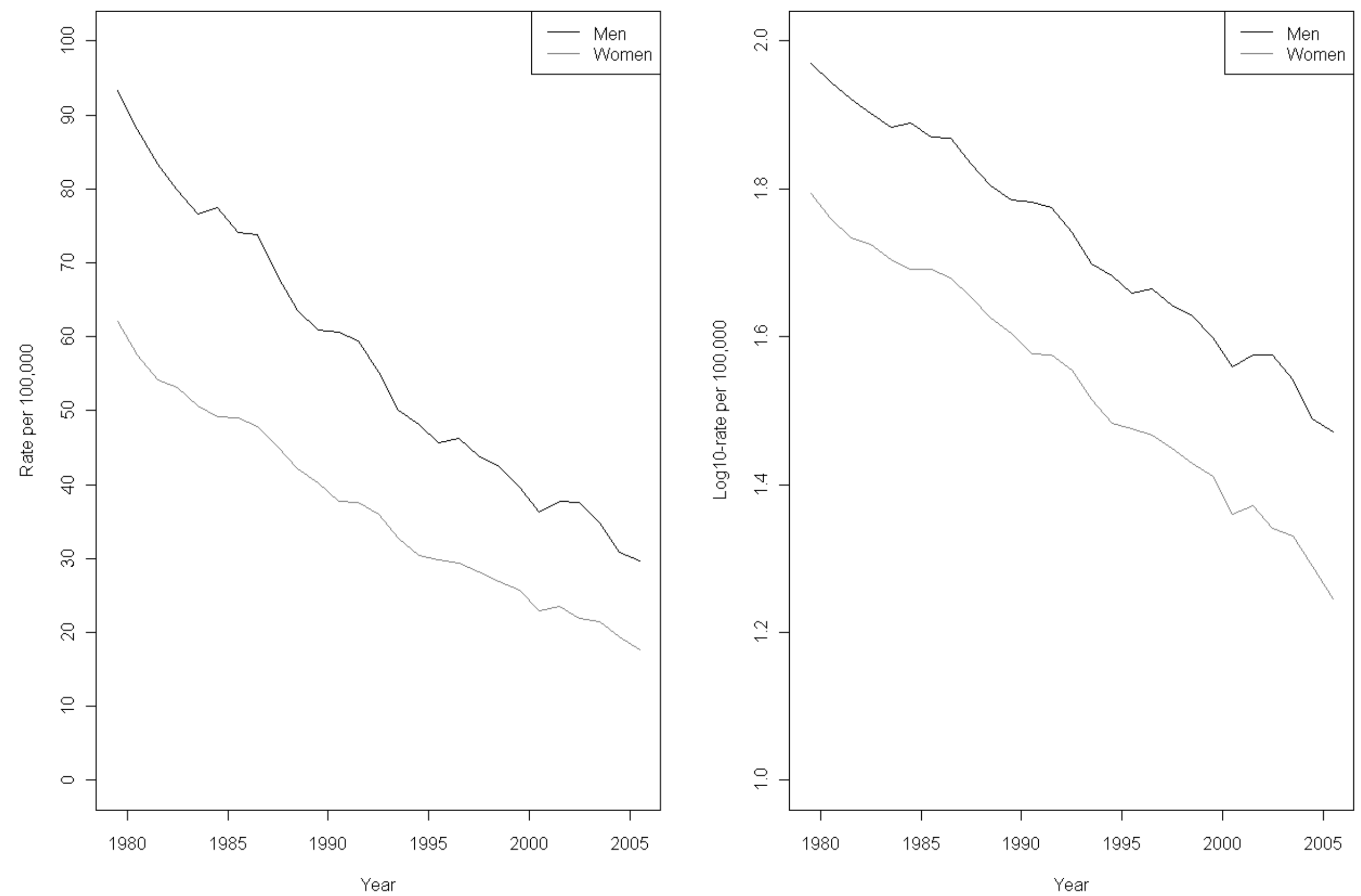

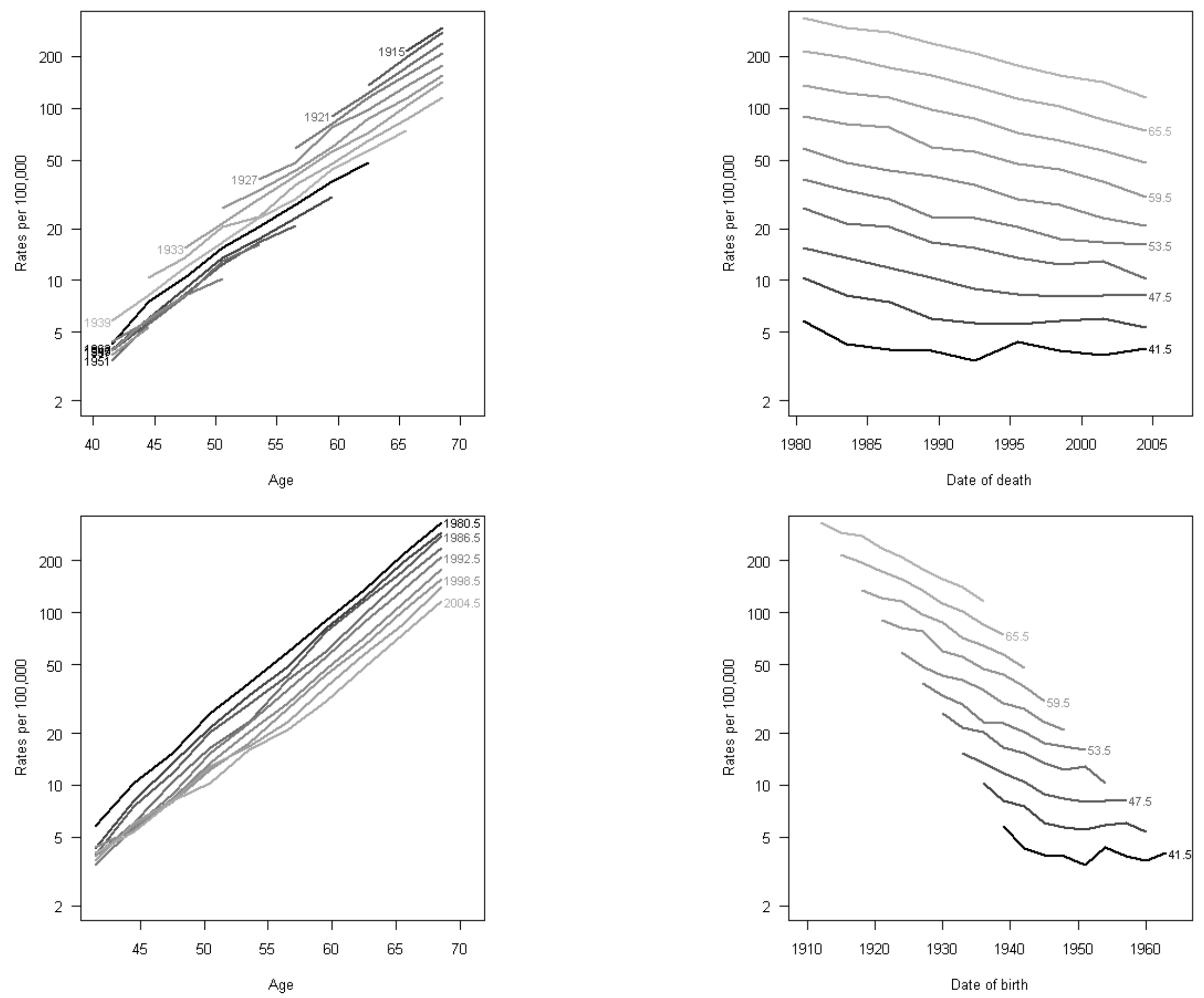

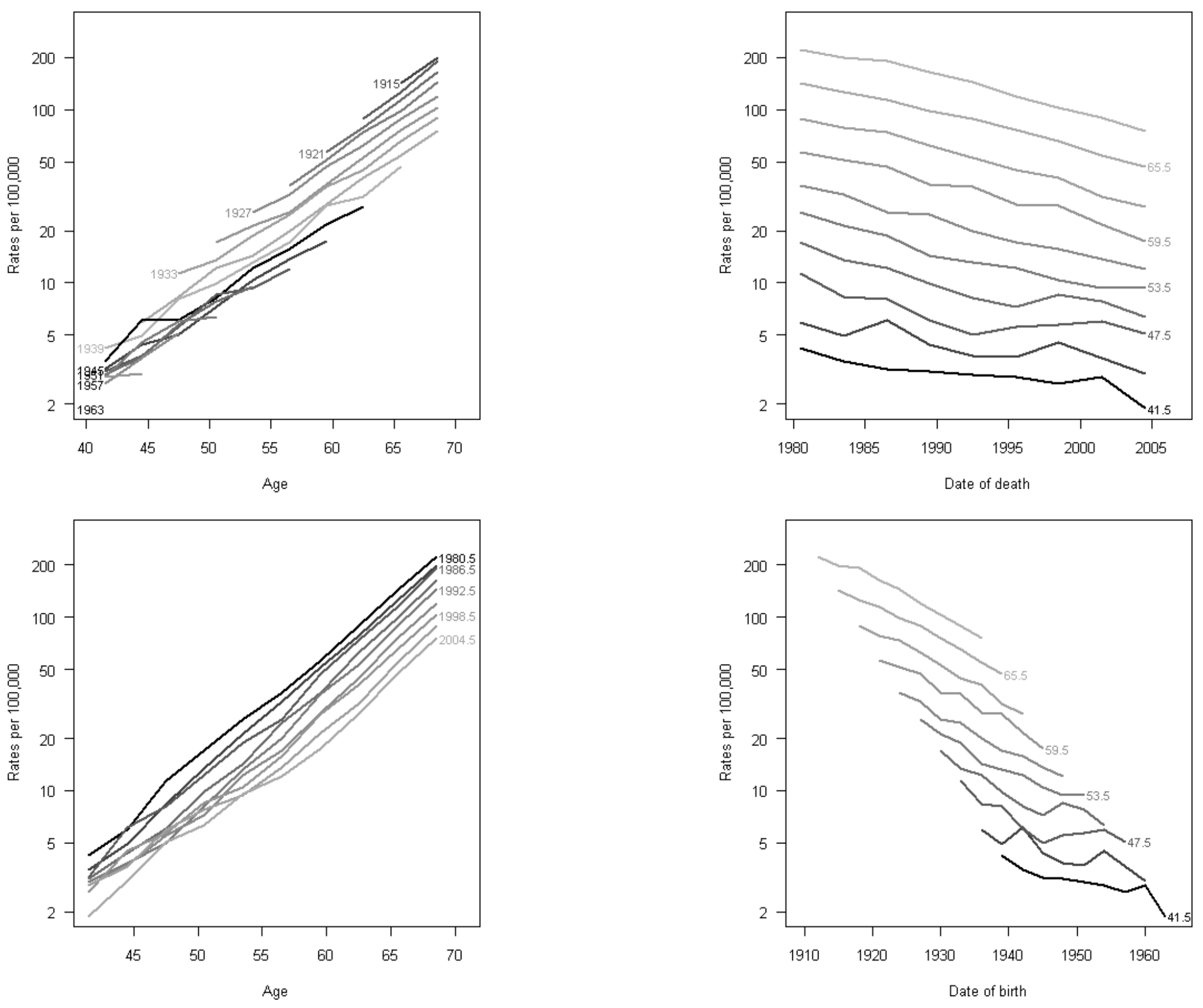
Men

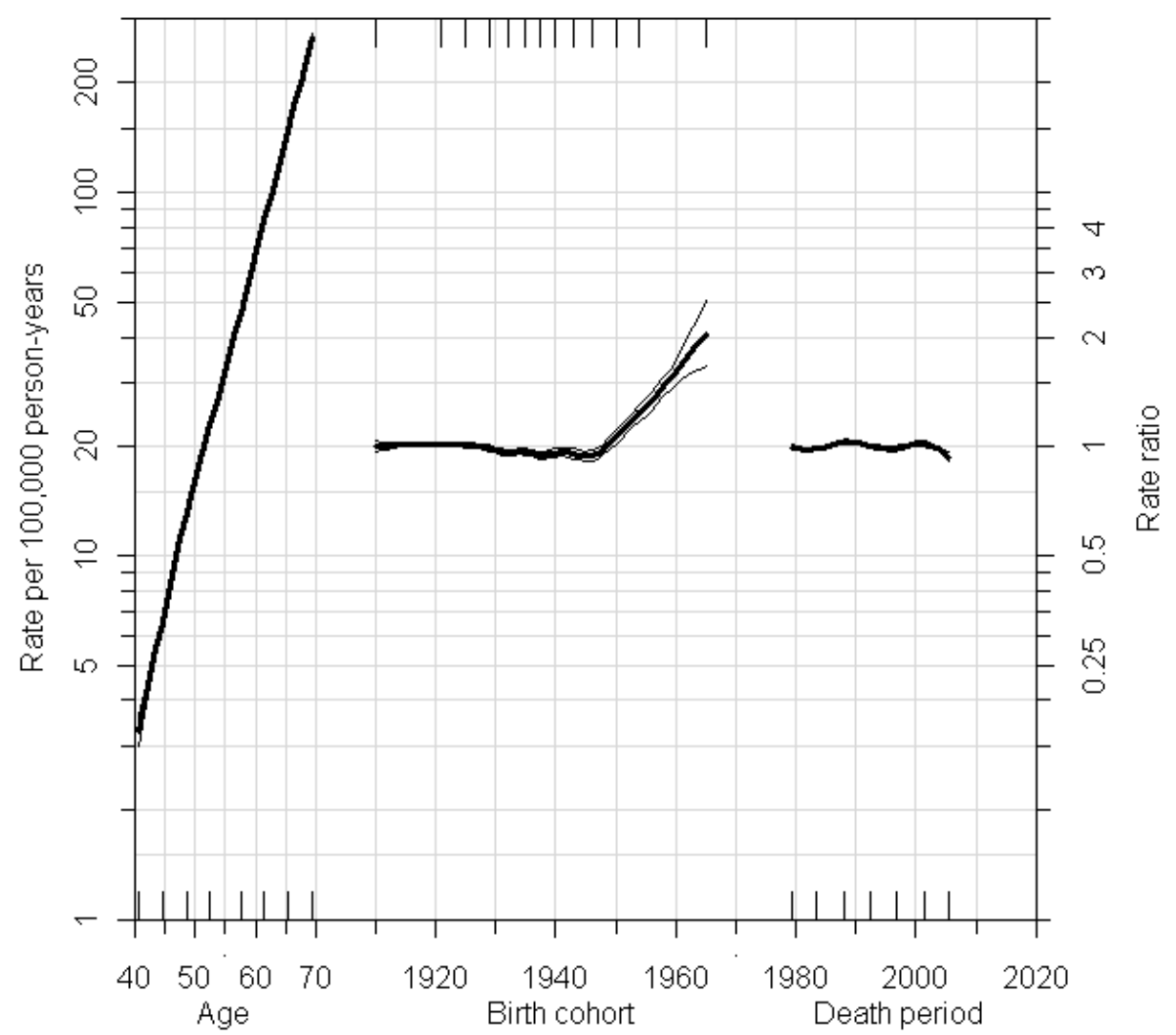

Women

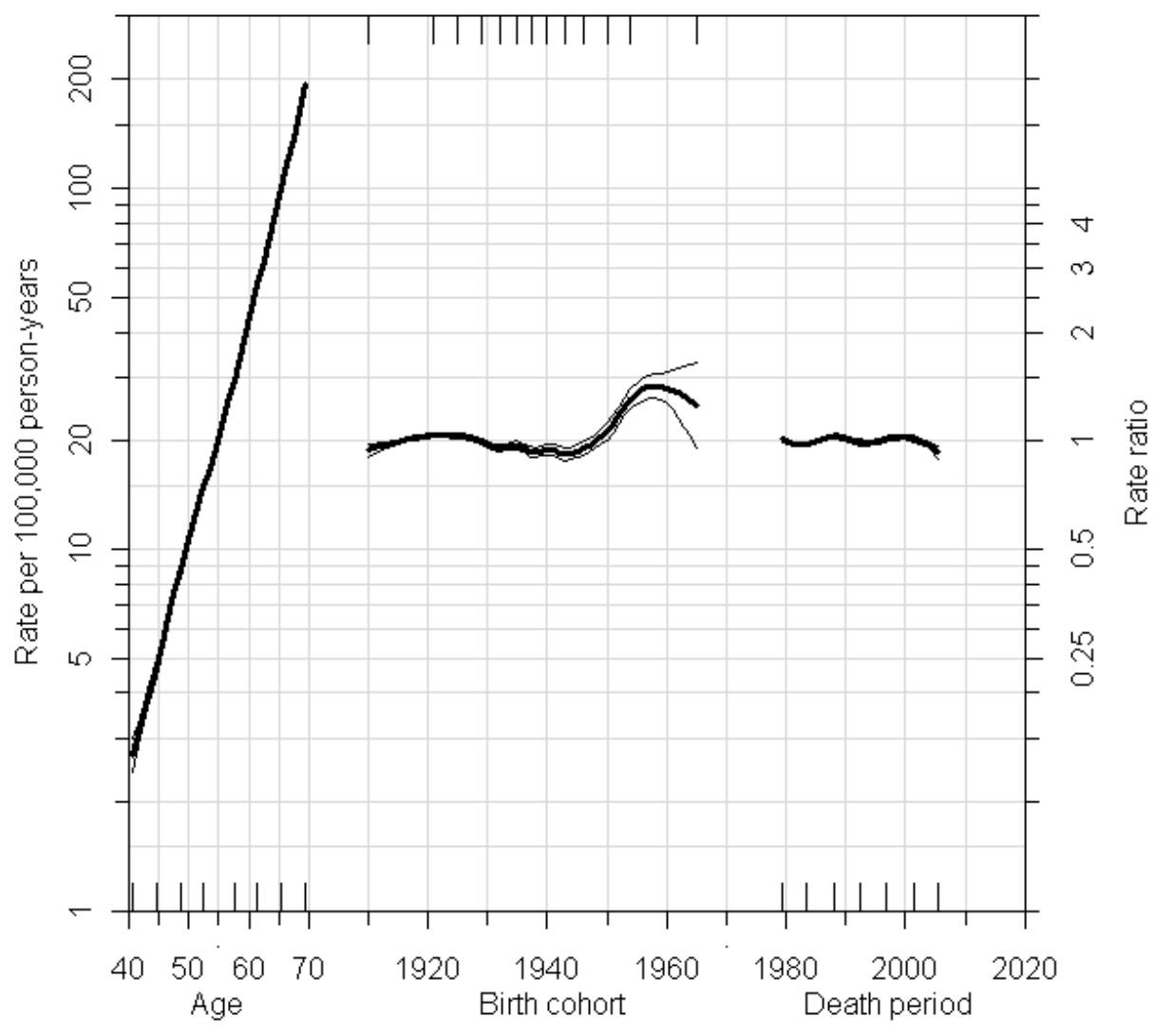


Men

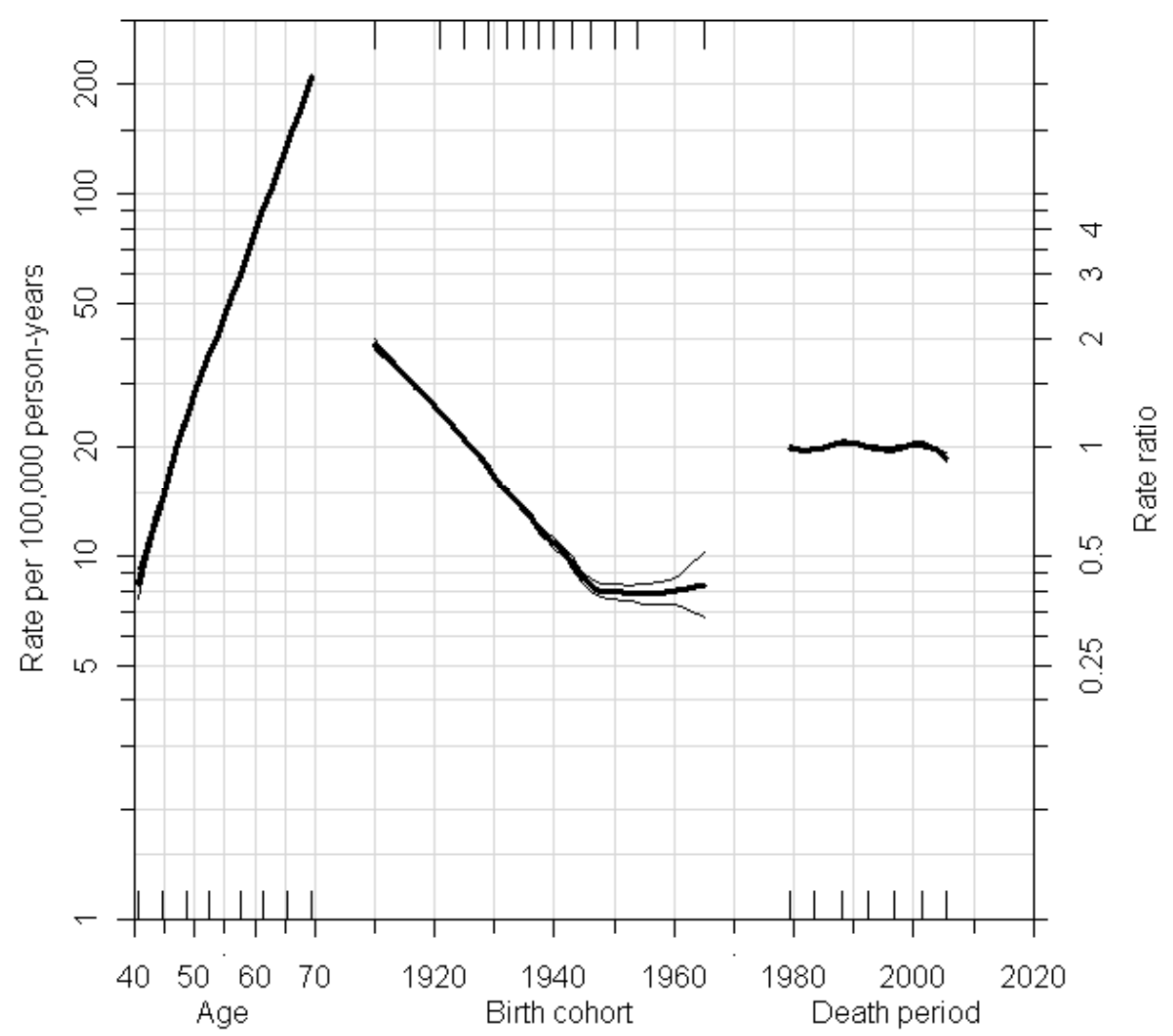

Women

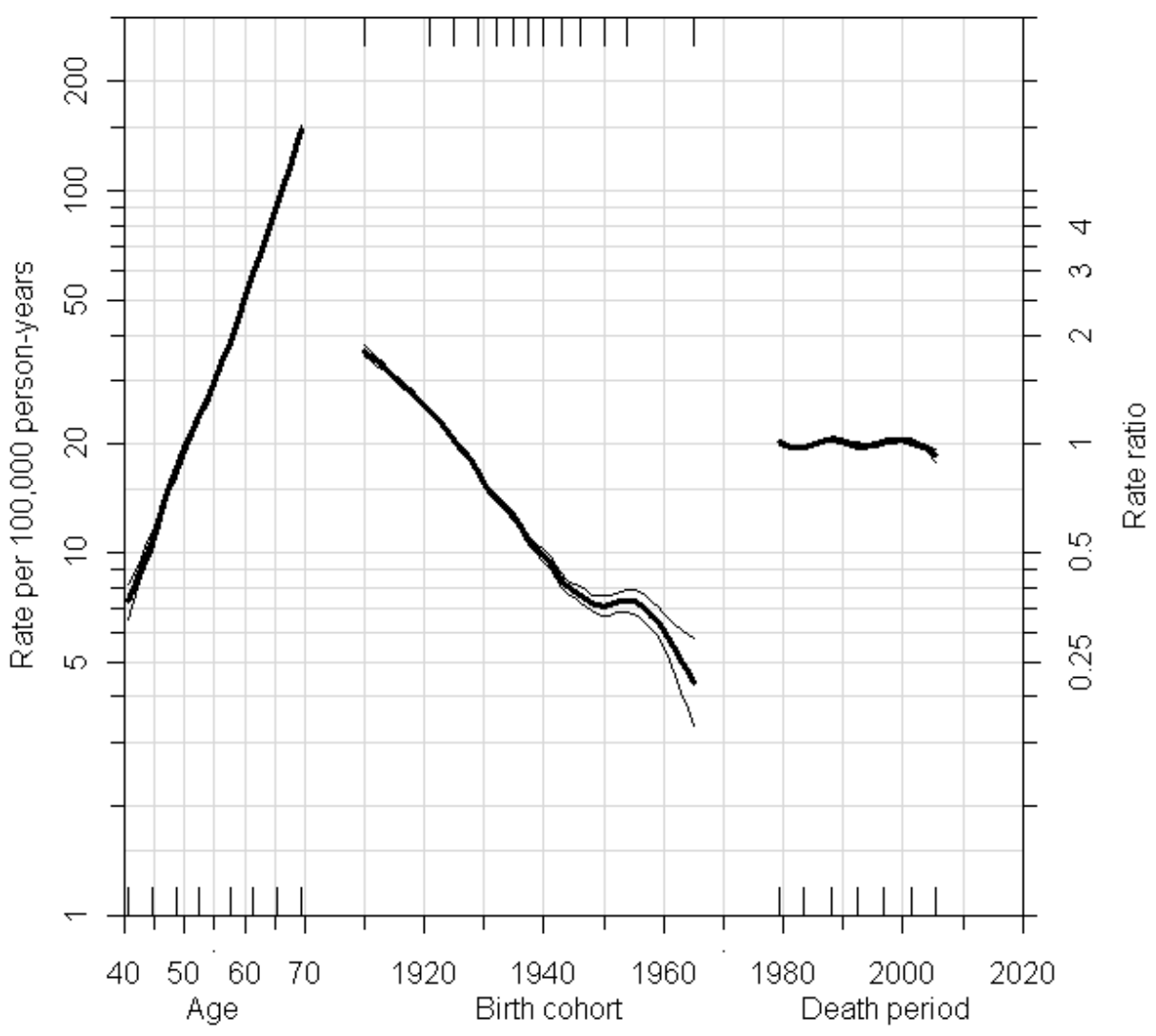

